\title{
Teacher Ethics: \\ The Link between Quality Teaching and Multi-ethnic and Multiracial Education
}

\author{
By Helen J. Boon* \\ Brian E. Lewthwaite
}

\begin{abstract}
Many current economic and social challenges lead to waves of migrating people. The countries where migrants seek refuge can be ethnically homogeneous and monolingual such as Greece, or more frequently, ethnically diverse with local Indigenous populations which have been subjugated and marginalized, such as the US or Australia. In either context, a significant corollary of migration is the absorption of children into the local educational system. Migrant children, much like the local Indigenous marginalized children of the host countries, have language barriers and different customs from those of the host country. Cultural mismatches between the culture of the child and that of its teacher have been empirically shown to result in a range of negative outcomes for the child, including behavioural infractions, low academic outcomes and dropping out of school. This research illustrates findings from the second phase of an extended study. The study aim was to identify what constitutes culturally responsive pedagogy in Australia to support the needs of Indigenous Australian students. Indigenous Australian students, like their counterparts in New Zealand and North America, have the lowest academic attainment of any students in Australia. Through qualitative interviews with Indigenous parents, teachers and students, we identified a range of teacher behaviours deemed by Indigenous people to be indicators of teacher quality as indicated by culturally responsive pedagogy. From these we constructed a teacher survey which was piloted with two waves of practicing teachers. Latent Trait Analyses using the Rasch Model validated the survey and its underlying factors. Findings showed that teachers' ethic of care strongly predicted their pedagogical expertise. Implications of the research include redefining quality teaching as a pedagogy based on strong ethical standards driven by a vocational disposition which seek to benefit all students including those from ethnically diverse groups such as Indigenous students, refugees and recent migrants.
\end{abstract}

Keywords: culturally responsive pedagogy, indigenous students, latent trait analysis, rasch model, refugees

\section{Introduction}

\section{The Need for a Multicultural Approach in the Classroom}

Western countries are currently facing rapid population shifts driven by migration arising from economic or political drivers, to escape poverty, war,

\footnotetext{
${ }^{*}$ Senior Lecturer, James Cook University, Australia.

${ }^{\dagger}$ Professor, James Cook University, Australia.
} 
oppression or persecution. Political changes, and the problems that are often associated with poor and authoritarian political governance, are driving waves of refugees all over the world in numbers rarely seen before. Furthermore it is predicted that due to climate change induced disasters climate refugees from developing countries will become an increasingly large proportion of migrants in the next few decades (King et al., 2014). As a case in point, Europe's population is fast changing as ethnic, racial, religious and economic diversity increases due to global economic forces and migration. In 2011, there were 33.3 million foreign citizens residing in the EU-27, representing $6.6 \%$ of the total population (Eurostat, 2012). The latest OECD report (2015) indicates that on average across OECD countries in 2012, $11 \%$ of 15 -year-old students had an immigrant background. Around $55 \%$ of these students were secondgeneration immigrants while $45 \%$ were first-generation immigrants, that is both they and their parents were born abroad in a country other than the one where they took their PISA tests. In terms of the academic outcomes of these migrant students, the 2015 OECD report synthesised data which shows that in most countries immigrant students perform poorly; first generation immigrant students' outcomes are worse than those students without an immigrant background, and second generation immigrant students perform somewhere between the two.

The reasons for the poorer outcomes of immigrant students are complex, entangled with socioeconomic factors. Across OECD countries students who attend schools where the concentration of immigrants is high (i.e. where more than a quarter of students are immigrants) tend to perform worse than those in schools with no immigrant students. The OECD average for the observed difference between these two groups is 18 score points, but after accounting for the socio-economic status of the students and schools, the difference is more than halved, to 5 score points. However, Belgium and Greece are the only OECD countries with immigrant student populations of over $10 \%$, where the performance gap is large both before and after accounting for socio-economic status (40 and 30 score points, respectively). Many immigrant students are subject to multiple sources of disadvantage since they live in households with fewer resources and worse living conditions than native students. Their parents are often poorly educated; but even when this is not the case, their qualifications may not be recognised in their host country or they may have to work in low-skill jobs because of poor language skills, lack of formal contacts in their host community and so on (OECD, 2015). Language barriers are another reason for poorer academic outcomes since, on average, $64 \%$ of first-generation immigrant students and $41 \%$ of second-generation immigrant students speak a language at home that is different from the language of instruction (OECD, 2015). This situation is mirrored also in Indigenous Australians where English can be a second or third language for them (Perso \& Hayward, 2015). Language barriers are responsible for reading disadvantages even after the confounding factor of socioeconomic status has been portioned out. Among students of similar socio-economic status, those who do not speak the language of instruction at home perform at a lower level in reading than their problem solving skills would suggest. For example in Brazil, Portugal and Shanghai-China, the 
performance disadvantage in reading compared to the potential these students show in the problem-solving assessment is larger than 50 score points - the equivalent of almost one-and-a-half years of instruction (OECD, 2015).

The immense diversity of cultures reflected in school classrooms means teachers face the challenge of teaching increasingly multiethnic and multiracial classes, where students might differ not only in their background knowledge, but also in the strategies they use to approach and solve problems. Teachers who are not fully aware of these differences, who "play down" cultural differences, preferring instead to argue about ability, are ill-equipped to build on their students' knowledge and experiences. Indeed, research shows that teachers, schools and the public in general, hold a deficit view towards immigrant students and their families (Civil, 2008), as well as to Indigenous students (Perso \& Hayward, 2015). As a result, the focus is on what immigrant and Indigenous students cannot do or do not know, which mostly stems from not knowing the language of instruction. Little research documents experiences that centre on diversity and multiculturalism as a resource for learning (Civil, 2008). Indeed, many teachers recognise that handling cultural diversity in class is difficult and requires preparation in order for their pedagogies to be adapted successfully to educate all students (OECD, 2015). Teachers in several countries called for more professional development for teaching in multicultural or multiracial settings (OECD, 2015), particularly in countries like Italy and Spain, which recently saw rapid increases in the linguistic and cultural diversity in schools.

Research has shown that teachers have the potential to significantly influence student outcomes (Hattie, 2009). The influence that a teacher has is however, laden with messages that are perceived by recipient students at a level that is not overt but rather implied by teacher (in)action, which is often founded on low expectations (Rubie-Davies, Hattie, \& Hamilton, 2006). For example, Perso and Hayward (2015) argue that students from different cultures, including Indigenous students, feel that they are treated differently on the basis of their phenotypic characteristics. These impressions are based on teachers' low expectations of these students implicitly conveyed by behaviours such as giving those students busy work to do - copying or worksheets that do not demand problem solving or higher order thinking; making comments such as "these are really good results for these kids"; having posters around the classroom which do not include the Indigenous or the other cultural groups represented in the class; talking to students outside the classroom but not to Indigenous or those from other cultures, and so on. In addition, the behavioural sanctions often applied to Indigenous and other cultural groups, sanctions which are closely linked to underachievement and dropping out, have been connected strongly with the cultural mismatch between teacher and student (Gregory, Skiba, \& Noguera, 2010). Certainly in Australia Indigenous students have for a very long time been achieving well below the level of other students and at the same time experience a consistently higher rate of disciplinary sanctions, suspension and expulsions (Perso \& Hayward, 2015), reflecting similar trends to those observed in the United States (Gregory, Skiba, \& Noguera, 2010). In all, international data indicates that students from minority ethnic groups in 
OECD countries are not receiving quality teaching that caters to their needs.

\section{Quality Teaching}

Teacher quality and teaching quality are both characterised by pedagogy designed to maximise student learning by catering for individual's needs. Teaching has been found to be most effective when the cultural heritages, prior experience, and performance styles of students are incorporated into the instructional process (Banks, 2010; Ladson-Billings, 2009). But these dimensions are often ignored in the instructional process (Gay, 2010) and teaching continues along Eurocentric agendas. On the other hand factors that have been implicated in the less than optimum teaching for minority students, and their over selection for discipline include cultural mismatch, implicit bias, and low expectations in classrooms and schools (Gregory et al., 2010; Gay, 2010; Perso \& Hayward, 2015).

In order to effectively modify their pedagogy to improve the learning of minority multiethnic students, teachers must understand and value the diversity that these children bring with them into classrooms. Incorporating a multicultural approach to the teaching and learning process requires the teacher to be aware of the cultural, ethnic, and in the case of Australia, New Zealand, Canada and the United States, the Indigenous practices of students, and then to use a range of those practices as the basis upon which to scaffold the learning of individual lessons and units of work as Vygotsky advocated decades ago (Vygotsky, 1978). As early as the 1930s culturally responsive pedagogy was central to Vygotsky's theory which advocated for the use of cultural tools for the facilitation of learning. This is differentiation which, in the case of Australian Indigenous students, might mean an emphasis on collaboration, cooperation and small-group organisation as the basis for forming learning structures within the classroom. Incorporating such pedagogies is important for Australian Indigenous students' achievement as they help advance their selfconcept as learners, a critical factor for their academic engagement (Purdie \& McCrindle, 2004; Purdie et al., 2000). Critically too, in order for teachers to make such adjustments to their teaching, they must have an understanding of the way the dominant White culture defines acceptable processes of teaching and learning and their purpose and how it privileges those belonging to it (Acquah, 2015). Teachers must also have the dispositions and ethical orientations that place value on individuals of whatever colour or creed, demonstrated by a highly developed ethic of care (Snook, 2003).

\section{The Present Study}

\section{Aims and Methods}

In an effort to help teachers to improve their pedagogy for students from diverse backgrounds we focused on instruction processes and classroom dispositions that Australian Indigenous students and their parents endorsed as 
being helpful for their learning. To that end we followed a two phase research protocol reported fully in Boon and Lewthwaite (2015), as a precursor to a third forthcoming intervention phase. We conducted interviews with 27 Indigenous parents, 43 grade 9-12 students and also with Indigenous teachers and a teacher administrator responsible for curriculum delivery and appropriate pedagogical practice for Indigenous students and gathered information about the specific classroom behaviours that typified quality teaching for Indigenous students. These behaviours were endorsed as being culturally sensitive and responsive to Indigenous students' cultural identity and ways of learning.

Extensive thematic analysis of the interviews led to the emergence of 7 categories of behaviour that describe qualitatively the pedagogical characteristics identified as being important for Indigenous learners (Table 1). Because of their focus on student needs and cultural sensitivity, we believe these behaviours will support learning for diverse student groups. We describe the pedagogy derived thus as Culturally Responsive Pedagogy (CRP) in line with other researchers (e.g., Gay, 2010).

Table 1. Culturally Responsive Pedagogy (CRP) Characteristics

\begin{tabular}{|l|l|}
\hline Category & \multicolumn{1}{|c|}{ Description and Examples } \\
\hline Ethic of care & $\begin{array}{l}\text { An ethic of care is the foundation for all teaching practices. } \\
\text { Teaching is characterised by respectful, positive and warm } \\
\text { interactions with students. }\end{array}$ \\
\hline Cultural value & $\begin{array}{l}\text { Valuing students' cultural identity, showing respect for students' } \\
\text { home language and having cultural knowledge which is used to } \\
\text { scaffold children's learning. }\end{array}$ \\
\hline Literacy teaching & $\begin{array}{l}\text { Literacy is explicitly taught from a foundation of spoken language. } \\
\text { Code switching between Aboriginal English and Standard } \\
\text { Australian English is explicitly taught. Reading strategies and } \\
\text { writing are focused upon and repeatedly modelled in context. }\end{array}$ \\
\hline $\begin{array}{l}\text { Explicit teaching } \\
\text { practices }\end{array}$ & $\begin{array}{l}\text { Expectations of behaviour and achievement are clearly and } \\
\text { repeatedly communicated to students. The knowledge and skills } \\
\text { needed by students are explained and modelled in a variety of ways; } \\
\text { feedback is regularly offered. }\end{array}$ \\
\hline Pedagogical expertise & $\begin{array}{l}\text { The teacher behaves as a learning facilitator; students are given } \\
\text { choices, open ended, experiential, group and outside activities from } \\
\text { which to learn. Visual imagery is used to prompt engagement and } \\
\text { support learning. Information and skills are chunked and scaffolded, } \\
\text { and connected to prior knowledge. }\end{array}$ \\
\hline regulation & $\begin{array}{l}\text { Students contribute to the setting of classroom expectations, which } \\
\text { are clearly and consistently communicated to students. Use of } \\
\text { cooperative learning behaviours, engaging and accessible tasks and } \\
\text { established routine decrease the need to manage student behaviours. }\end{array}$ \\
\hline Source: Adapte
\end{tabular}

Source: Adapted from Boon \& Lewthwaite, 2015, p. 41. 


\section{Instrumentation Process and the Use of the Rasch Model}

The next phase of the study involved generating items pertaining to the qualitative categories of the CRP in order to construct an instrument that could be applied to a large cohort of teachers for validation. The items were generated by a process of cross-referencing the theoretical and empirical literature with the interview results. We then reviewed the items with experts in the fields of psychology and psychometrics, and educators responsible for the curriculum development for Indigenous students. As a result the research team generated 83 items for the initial instrument. The constructed CRP instrument was then piloted with 141 teachers and a further 79 teachers for replication using the online format, SurveyMonkey.

The instructions given to participants were the following: "The statements in this questionnaire deal with the actions or behaviours that might be seen or used in the classroom. Answer the questions based upon the degree you believe these actions or behaviours are used in your classroom. There are 5 possible answers for each behaviour ranging from 'almost never' to 'almost always'. Please be honest and accurate in your answer."

In responding to the instrument the teacher were required to select an answer from a Likert scale format with the following response format:

Almost never $<20 \%$ of the time

Once in a while: $20-39 \%$ of the time

Sometimes: $40-59 \%$ of the time

Frequently: $60-79 \%$ of the time

Almost always $\geq 80 \%$ of the time

The only demographic information which was sought was whether the teacher was a secondary or elementary teacher. The sample upon which we tested the instrument consisted of 80 elementary and 61 secondary school teachers. For extensive statistical details of the piloting phase using Rasch analyses to validate the instrument please refer to Boon and Lewthwaite, (2015). The validation process of the instrument resulted in 62 well-fitting items (Table 2). 
Table 2. Instrument Factors and Items

\begin{tabular}{|c|c|}
\hline tor & Items used to assess factor \\
\hline & $\begin{array}{l}\text { 1. I ensure that students know that their success and value is not } \\
\text { determined only by academic achievement } \\
\text { 2. I have a warm respectful manner to all students } \\
\text { 3. I spend individual time with all students in matters pertaining to } \\
\text { their learning } \\
\text { 4. I communicate high academic expectations for students } \\
\text { 5. I engage with all students in positive conversation in matters that } \\
\text { display evidence of my interest in the student } \\
\text { 6. I explicitly encourage learner development in the broad sense not } \\
\text { 7. I post academic learning } \\
\text { 8. Learning acknowledge all students verbally or non-verbally } \\
\text { 9. I display positive gestures e.g. smiles towards all students }\end{array}$ \\
\hline & $\begin{array}{l}\text { 10. Individual scaffolding is provided to all students so each can } \\
\text { perform required learning tasks } \\
\text { 11. I ensure my explanations are succinct } \\
\text { 12. The learning priorities of the classroom are made clear } \\
\text { 13. Learning objectives are displayed and articulated } \\
\text { 14. I give constructive individual feedback } \\
\text { 15. The.learning.focus.for.lessons.is.orally.communicated.throughout.l } \\
\text { essons }\end{array}$ \\
\hline & $\begin{array}{l}\text { 16. Buddy reading occurs } \\
\text { 17. The vocabulary and language of each curriculum area are explicitly } \\
\text { taught } \\
\text { 18. Literacy skills are taught and practiced in the context of modelled } \\
\text { age appropriate text } \\
\text { 19. ESL strategies are used when teaching students learning English as } \\
\text { a second or additional language } \\
\text { 20. Basic literacy skills are regularly revised } \\
\text { 21. I orientate students to the vocabulary background knowledge and } \\
\text { features of a text before reading } \\
\text { 22. Oral language is used to develop literacy competence in SAE }\end{array}$ \\
\hline & $\begin{array}{l}\text { 23. Skills and behaviours are modelled for students } \\
\text { 24. I address off task behaviour with less intrusive correction skills } \\
\text { such as non-verbal cues and proximity } \\
\text { 25. Students are able to contribute to the setting of the behavioural } \\
\text { expectations for the classroom } \\
\text { 26. Routines provide students with foreknowledge of activities and } \\
\text { expectations } \\
\text { 27. Consequences for student behaviour are made clear } \\
\text { 28. I communicate and follow through on expectations about expected } \\
\text { classroom behaviour } \\
\text { 29. I communicate high behavioural expectations for students }\end{array}$ \\
\hline
\end{tabular}




\begin{tabular}{|c|c|}
\hline $\begin{array}{l}\text { Self- } \\
\text { regulation } \\
\text { Support }\end{array}$ & $\begin{array}{l}\text { 30. Students are given time to think things through in their own minds } \\
\text { 31. I use individual student's strengths to support individual and } \\
\text { collective learning } \\
\text { 32. Lessons are paced to allow students time for task completion } \\
\text { 33. Students reflect on their goal achievement } \\
\text { 34. Time is given for students to respond to questions or during } \\
\text { discussion } \\
\text { 35. Individual goals for student achievement are established } \\
\text { 36. Students work together and help others on activities and problems } \\
\text { 37. Students are given choices about work e g modes content timing } \\
\text { order of tasks where to work } \\
\text { 38. Students conduct self-assessments of work completed } \\
\text { 39. I act as a learning facilitator } \\
\text { 40. Students are provided with time to ensure mastery of ideas }\end{array}$ \\
\hline & $\begin{array}{l}\text { 41. Many examples are provided to support students in their learning } \\
\text { 42. Tasks carried out encourage student creativity and independent } \\
\text { thinking } \\
\text { 43. I use multiple strategies to assist students in their learning } \\
\text { 44. Intervention is provided for those students not achieving the } \\
\text { expected attainment for their age cohort } \\
\text { 45. Students show their learning in various ways not just written } \\
\text { 46. Learning and assessment are placed within the broader contexts of } \\
\text { what is familiar to students } \\
\text { 47. Learning experiences that cater for a variety of learning } \\
\text { preferences are provided } \\
\text { 48. Learning is chunked into short teaching segments } \\
\text { 49. Hands on experiential activities are provided to support learning } \\
\text { 50. I model thinking processes aloud } \\
\text { 51. Multiple methods are used to explain abstract ideas } \\
\text { 52. Students are provided with many opportunities to master skills } \\
\text { 53. Narrative and story are used across the content areas } \\
\text { 54. Open ended learning activities are provided } \\
\text { 55. Visual images are used to support understanding of ideas }\end{array}$ \\
\hline $\begin{array}{l}\text { Indigenous } \\
\text { Cultural } \\
\text { Value }\end{array}$ & $\begin{array}{l}\text { 56. Students specific cultural identities are valued in this classroom } \\
\text { 57. I communicate personally with families } \\
\text { 58. Resources with local Indigenous content are provided } \\
\text { 59. Cultural values are verbally endorsed } \\
\text { 60. Relatives and community Elders are invited to contribute to or } \\
\text { observe classroom learning } \\
\text { 61. Contemporary Aboriginal and Torres Strait Islander perspectives } \\
\text { are included in all subject areas } \\
\text { 62. Local community has input into curriculum content and process }\end{array}$ \\
\hline
\end{tabular}

Note: Adapted from Boon \& Lewthwaite, 2015, p.52.

In brief, Rasch analyses were deemed to be most appropriate for the validation of the instrument because although Classical test Theory (CTT) is widely used in the construction of survey instruments It has two major limitations. First, the lack of an explicit ordered continuum of items that 
represent a unidimensional construct, and second, the lack of additivity of rating scale data. These made it unsuitable for the development of this instrument. By using the Rasch model we were able to place the items on a measurement scale which then enabled us to: i. Examine the hierarchical structure of the factors comprising the instrument, ii. Ensure that the underlying, or latent factor culturally responsive pedagogy (CPR) was comprised of only one dimension, that is, that it was unidimensional, and iii. That the measures of the CRP and item parameters were invariant across populations, that is that they were independent of the sample. When an instrument like the CRP satisfies the required assumptions of the Rasch model, the instrument can reliably and validly be used for measuring the latent trait in question, in this case teachers' endorsement of culturally responsive pedagogy (CPR). The creation of interval-level data, invariant items and the sample independence features of the Rasch model overcome the fundamental drawbacks of the classical test theory (CTT) analyses. For the purposes of this research, this means that a teacher can be placed on the CRP continuum and his/her location will denote a level of endorsement of CRP that can be described by the types and level of items that correspond to their personal score. Further, a teacher might chose to modify their pedagogy in light of their measured CRP score by focusing on specific behaviours represented by items on the CRP survey, thus modifying particular facets of their CRP.

Rasch analyses (Bond \& Fox 2007) were used to quantify each respondent's score for each factor within the CRP, by transforming their ordinal response data to log-odds ratios, or logits. The interval measures obtained thus for each participant on each factor were then modelled using AMOS structural equation modelling (SEM) on the IBM SPSS 20 software to estimate the influence of an ethic of care upon the other factors and obtain a hierarchical ordering of the various factors of the instrument.

\section{Results}

The results reported here are specifically concerned with the links between the underpinning factors of the CRP as endorsed by practicing teachers. Table 3 shows results of a Pearson's correlation analysis and the links between the different factors of CRP in the piloting wave of the instrument. Results indicated that Indigenous cultural values and an ethic of care were highly correlated with pedagogical expertise and literacy teaching, both important underpinning skills characterising quality teaching as indicated by interviews of Phase One.

One of the advantages of using the CPR instrument is that it enables teachers to reflect upon their pedagogy and apply modifications to particular aspects of their teaching. It is easy, for example, for an individual teacher to see how their usual pedagogy is characterised through their application of the seven factors of culturally responsive teaching. By way of illustration Figure 1 shows how three different teachers with an identical overall CRP score have 
unique emphases. These variations illustrate that teachers can adjust particular aspects of their pedagogy to better fit the needs of their students in the classroom, whether this is because their students are of a minority ethnic group, Indigenous, or needing specific language support because of having a different home language than that spoken at school, or because attention needs to be focused on helping those with particular learning disabilities. In other words differentiation of a teacher's pedagogy is possible using this instrument.

Table 3. Pearson's Correlations between Subscales of CRP $(\mathrm{N}=138)$

\begin{tabular}{|c|c|c|c|c|c|c|c|}
\hline & $\mathbf{1}$ & $\mathbf{2}$ & $\mathbf{3}$ & $\mathbf{4}$ & $\mathbf{5}$ & $\mathbf{6}$ & $\mathbf{7}$ \\
\hline 1. ethic of care & 1 & $.656^{* *}$ & $.514^{* *}$ & $.673^{* *}$ & $.554^{* *}$ & $.583^{* *}$ & $.567^{* *}$ \\
\hline $\begin{array}{l}\text { 2. pedagogical } \\
\text { expertise }\end{array}$ & $.656^{* *}$ & 1 & $.676^{* *}$ & $.683^{* *}$ & $.694^{* *}$ & $.665^{* *}$ & $.682^{* *}$ \\
\hline $\begin{array}{l}\text { 3. literacy } \\
\text { teaching }\end{array}$ & $.514^{* *}$ & $.676^{* *}$ & 1 & $.542^{* *}$ & $.573^{* *}$ & $.469^{* *}$ & $.694^{* *}$ \\
\hline $\begin{array}{l}\text { 4. behaviour } \\
\text { support }\end{array}$ & $.673^{* *}$ & $.683^{* *}$ & $.542^{* *}$ & 1 & $.586^{* *}$ & $.579^{* *}$ & $.484^{* *}$ \\
\hline 5. explicitness & $.554^{* *}$ & $.694^{* *}$ & $.573^{* *}$ & $.586^{* *}$ & 1 & $.577^{* *}$ & $.477^{* *}$ \\
\hline \begin{tabular}{l} 
6. $\begin{array}{l}\text { self- } \\
\text { regulation } \\
\text { support }\end{array}$ \\
\hline $\begin{array}{l}\text { 7. Indigenous } \\
\text { cultural } \\
\text { value }\end{array}$
\end{tabular} & $.583^{* *}$ & $.665^{* *}$ & $.469^{* *}$ & $.579^{* *}$ & $.577^{* *}$ & 1 & $.443^{* *}$ \\
\hline
\end{tabular}

**. Correlation is significant at the 0.01 level (2-tailed).

Figure 1. Comparing 3 Teachers with Identical Overall Score on CRP
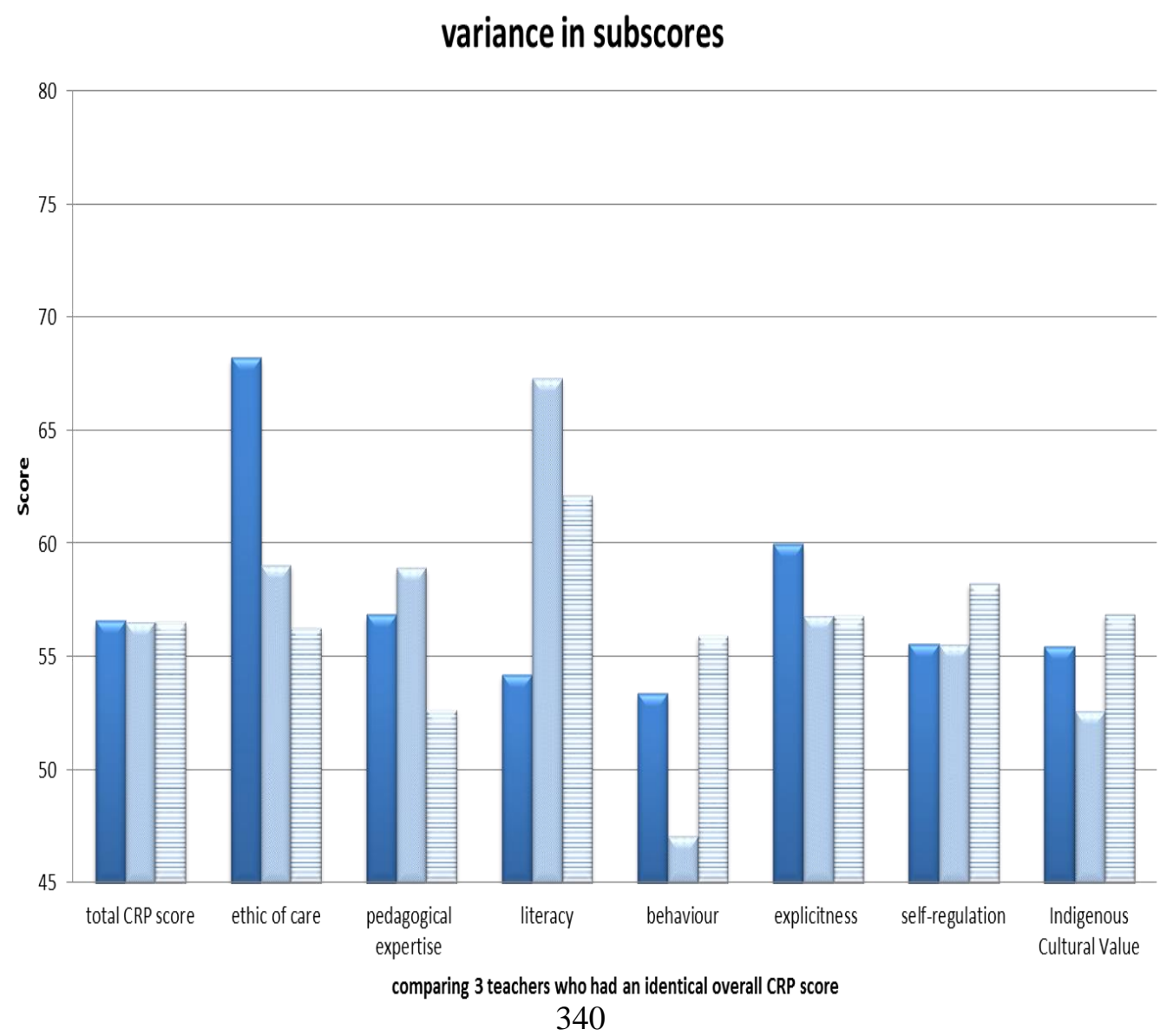
To examine the links between the various factors of the CRP and to gauge the influence of an ethic of care upon the pedagogical emphases of teachers, SEM was employed (Figure 2). Results of the modelling showed that an ethic of care is the precursor of pedagogical expertise (regression weight, standardised $\beta=0.66$ ) and behaviour support approaches (regression weight, standardised $\beta=0.40$ ). It also positively and directly predicts self-regulation support (regression weight, standardised $\beta=0.24$ ) and cultural values (regression weight, standardised $\beta=0.21$ ). Critically, it predicts cultural values indirectly via pedagogical expertise (regression weight, standardised $\beta=$ 0. 54), explicitness (regression weight, standardised $\beta=0.69$ ) and selfregulation support (regression weight, standardised $\beta=0.50$ ). Finally those who strongly support cultural values are also most likely to emphasise literacy teaching in their students (regression weight, standardised $\beta=0.50$ ) a critical matter for improving outcomes for ethnically diverse students.

Figure 2. Structural Equation Modelling of the Factors of the CRP $(\mathrm{N}=138)$

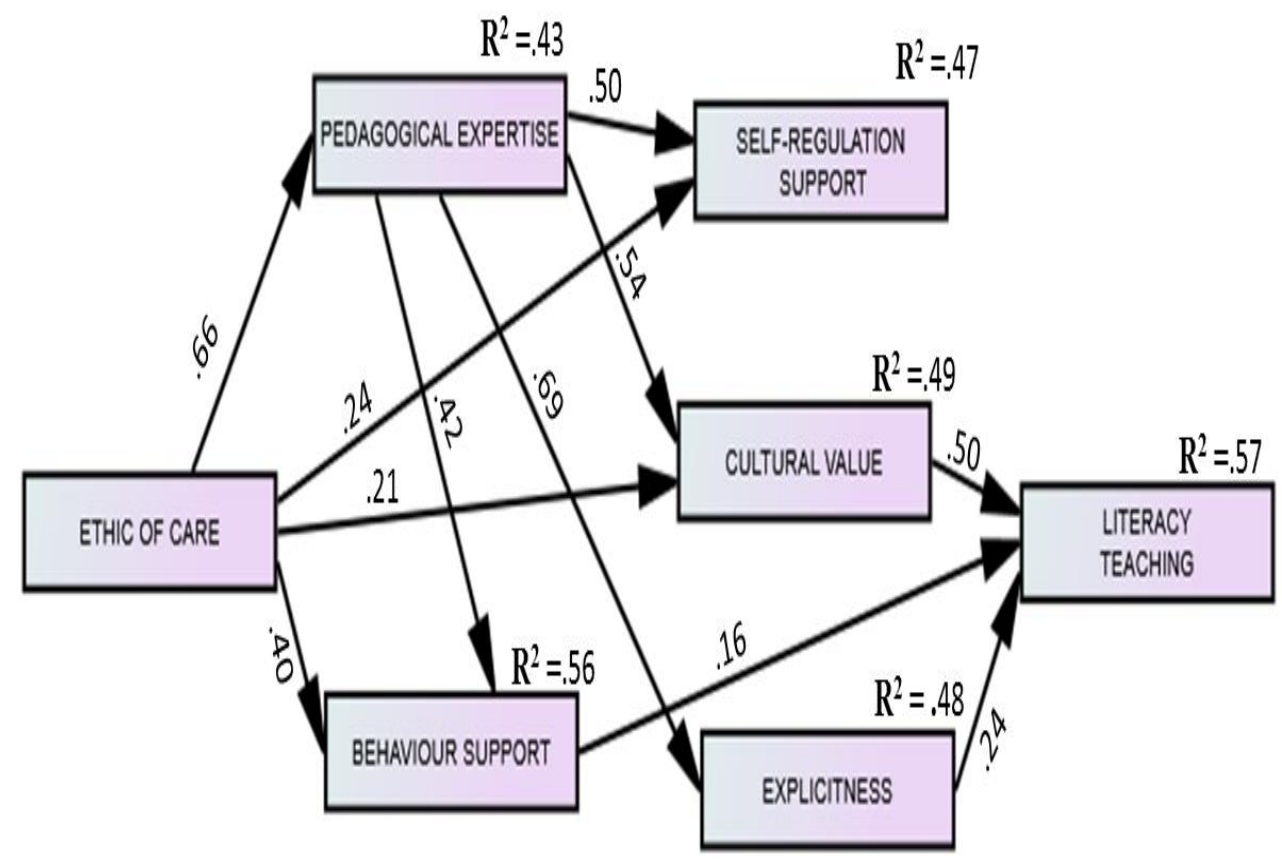

Significantly an ethic of care was predictive of behaviour support, strongly suggesting that those teachers who have a highly developed sense of an ethic of care for their students are more likely to seek appropriate ways to help students to manage their behaviours, avoiding disciplinary action which is so often highlighted in minority students' school profiles, and leads to school disaffection and poor outcomes (Gay, 2010; Perso \& Hayward, 2015).

This model accounted for $57 \%$ of the variance $\left(\mathrm{R}^{2}\right)$ in literacy teaching and $49 \%$ of the variance in cultural values. All regressions (standardised regression beta weights) are significant to $p=005$. The currently acceptable test 
for assessing goodness of fit of proposed structural equation models is the chisquare test (Heene, Hilbert, Freudenthaler, \& Bühner, 2012). The chi-square test $\left(\mathrm{chi}^{2}\right.$ ) tests the hypothesis that an unconstrained model (no direct arrows; variables related randomly) fits the covariance/correlation matrix as well as the given model. The chi-square $p$ value should not be significant if there is a good model fit (Kline, 2005). The model fit index for the proposed model above is good, $\mathrm{chi}^{2} / \mathrm{df}=1.97, p<0.10$.

\section{Discussion}

The findings reported here constitute one of a very few studies that have empirically investigated culturally responsive pedagogy. Moreover, CRP as described can define quality teaching for multiethnic and multiracial students who like Australian Indigenous students might have unique ways of learning but underachieve due to language barriers and a range of factors linked to socioeconomic disadvantage.

Quality teaching was empirically found to be based on factors that include explicit instruction, literacy teaching, which enhances language development, high teacher expectations communicated via pedagogical expertise and cultural value, and behavior support which helps to minimize disciplinary action based on cultural misunderstandings and low teacher expectations giving rise to self-fulfilling prophecy developments (Perso \& Hayward, 2015). With minimal rewording the items pertaining to the factor Indigenous cultural value could be adapted to fit with any number of multiethnic groups found in a classroom.

Findings here support the contention that quality teaching is based on an ethical disposition that respects and values cultural diversity and uses cultural knowledge as a teaching tool. A disposition which accepts that diversity enriches the classroom rather than brings a set of deficits to it. The European Commission $(2011 \mathrm{a} ; 2011 \mathrm{~b} ; 2013)$ also endorses this view; they maintain that quality teachers are best described as a complex combination of knowledge and understanding, skills and appropriate dispositions, or attitudes. Such an ethical disposition was operationalized as an ethic of care in this research; it was found to be highly correlated with uncontested attributes of quality teachers: explicit teaching, literacy teaching, behavior support, self-regulation support and pedagogical expertise. Quality teaching stems from viewing teaching as a vocation not merely an occupation, and as Caena (2011) found there is an empirically identifiable link which distinguishes good teaching from quality teaching; quality teaching is characterized by being ethically defensible, and is distinct from good teaching, which merely shows that learning took place.

Finally it is worth recalling that economic development is integrating businesses, families, intellects, and organisations into global affiliation. These changes bring different cultures together at virtually every level of society, in almost every country of the world. There are therefore immense benefits for all students in bringing into the classroom an understanding and value for diverse cultures. 


\section{References}

Acquah, E. O. (2015). Responding to changing student demographics in Finland: A study of teachers' developing cultural competence (Doctoral dissertation). Retrieved February 7, 2016 from http://bit.ly/2arktxb.

Banks, J. A. (2010). Multicultural education: Characteristics and goals. In J. A. Banks \& C. A. Banks (Eds.), Multicultural education: Issues and perspectives, 7th ed., pp. 1-30. New York,NY: Wiley.

Boon, H.J., \& Lewthwaite, B. (2015). Development of an instrument to measure a facet of quality teaching: culturally responsive pedagogy. International Journal of Educational Research, 72, 38-58.

Bond, T.G. \& Fox, C.M. (2007). Applying the Rasch model: fundamental measurement in the human sciences, $2^{\text {nd }}$ Ed. Erlbaum, Mahwah.

Caena, F. (2011). Literature review: Teachers' core competences: requirements and development. European Commission Thematic Working Group 'Professional Development of Teachers' (Brussels, European Commission). Retrieved from http://bit.ly/2aFwlIH.

Civil, M. (2008). Mathematics teaching and learning of immigrant students: A look at the key themes from recent research. Manuscript prepared for the 11th International Congress of Mathematics Education (ICME) Survey Team 5: Mathematics Education in Multicultural and Multilingual Environments, July 2008, Monterrey, Mexico. Retrieved from http://bit.ly/2arrfmu.

European Commission. (2011 a). Literature review teachers' core competences: requirements and development. Brussels: European Commission.

European Commission. (2011 b). Policy approaches to defining and describing teacher competences. Brussels: European Commission.

European Commission. (2013). Supporting teacher competence development for better learning outcomes. Brussels: European Commission.

Eurostat (2012). Statistics in focus: Population and social conditions. Retrieved from http:// epp.eurostat.ec.europa.eu/.

Gay, G. (2010). Culturally responsive teaching: Theory, research, and practice. New York, NY: Teachers College Press.

Gregory, A., Skiba, R. J., \& Noguera, P. A. (2010). The achievement gap and the discipline gap two sides of the same coin?. Educational Researcher, 39(1), 59-68.

Hattie, J. (2009). Visible learning: A synthesis of over 800 meta-analyses relating to achievement. London, UK: Routledge.

Heene, M., Hilbert, S., Freudenthaler, H. H., \& Bühner, M. (2012). Sensitivity of SEM fit indexes with respect to violations of uncorrelated errors. Structural Equation Modeling: A Multidisciplinary Journal, 19(1), 36-50.

King, D., Bird, D., Haynes, K., Boon, H., Cottrell, A., Millar, J., Okadac, T., Boxe, P., Keogh D. \& Thomas, M. (2014). Voluntary relocation as an adaptation strategy to extreme weather events. International journal of disaster risk reduction, 8, 83-90.

Kline, R.B. (2005). Principles and practice of structural equation modelling, 2nd Ed. NewYork: The Guilford Press.

Ladson-Billings, G. (2009). The dream keepers: Successful teachers of African American children, 2nd ed. San Francisco, CA: Jossey-Bass.

OECD (2015). Immigrant Students at School: Easing the Journey towards Integration, OECD Reviews of Migrant Education, OECD Publishing, Paris. http://dx.doi.org/10.1787/9789264249509-en.

Perso, T., \& Hayward, C. (2015). Teaching Indigenous students: Cultural awareness and classroom strategies for improving learning outcomes. Allen \& Unwin. 
Purdie, N., \& McCrindle, A. (2004). Measurement of self-concept among Indigenous and non-indigenous Australian students. Australian Journal of Psychology, 56, $50-62$.

Purdie, N., Tripcony, P., Boulton-Lewis, F., Fanshauve, J., \& Gunstone, A. (2000). Positive self-identity for Indigenous students and its relationship to school outcome. Canberra, ACT: Commonwealth of Australia. Retrieved from http://bit.ly/2aoZfvN.

Rubie-Davies, C., Hattie, J., \& Hamilton, R. (2006). Expecting the best for students: Teacher expectations and academic outcomes. British Journal of Educational Psychology, 76(3), 429-444.

Snook, I. (2003). The ethical teacher. Palmerston, NZ: Dunmore Press.

Vygotsky, L.S. (1978). Mind in society: The development of higher psychological processes. Cambridge, MA: Harvard University Press. 